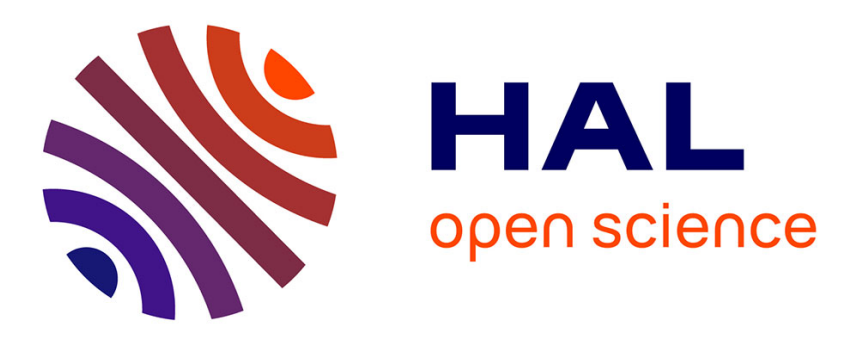

\title{
What do we learn from comparing hedonic scores and willingness-to-pay data?
}

Emilie Ginon, Pierre Combris, Youenn Loheac, Géraldine Enderli, Sylvie

Issanchou

\section{- To cite this version:}

Emilie Ginon, Pierre Combris, Youenn Loheac, Géraldine Enderli, Sylvie Issanchou. What do we learn from comparing hedonic scores and willingness-to-pay data?. Food Quality and Preference, 2014, 33, pp.54-63. 10.1016/j.foodqual.2013.11.003 . hal-00950490

\section{HAL Id: hal-00950490 https://hal.science/hal-00950490}

Submitted on 21 Feb 2014

HAL is a multi-disciplinary open access archive for the deposit and dissemination of scientific research documents, whether they are published or not. The documents may come from teaching and research institutions in France or abroad, or from public or private research centers.
L'archive ouverte pluridisciplinaire HAL, est destinée au dépôt et à la diffusion de documents scientifiques de niveau recherche, publiés ou non, émanant des établissements d'enseignement et de recherche français ou étrangers, des laboratoires publics ou privés. 


\section{Accepted Manuscript}

What do we learn from comparing hedonic scores and willingness-to-pay data?

E. Ginon, P. Combris, Y. Lohéac, G. Enderli, S. Issanchou

PII:

S0950-3293(13)00207-3

DOI: http://dx.doi.org/10.1016/j.foodqual.2013.11.003

Reference: FQAP 2703

To appear in:

Food Quality and Preference

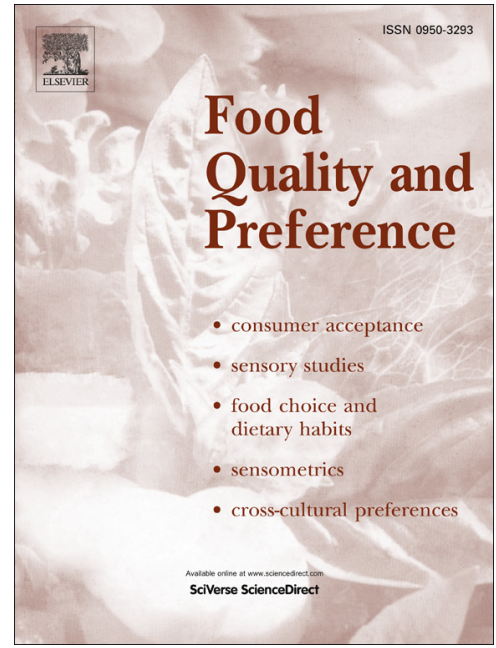

Received Date:

20 June 2012

Revised Date:

30 October 2013

Accepted Date:

13 November 2013

Please cite this article as: Ginon, E., Combris, P., Lohéac, Y., Enderli, G., Issanchou, S., What do we learn from comparing hedonic scores and willingness-to-pay data?, Food Quality and Preference (2013), doi: http://dx.doi.org/ 10.1016/j.foodqual.2013.11.003

This is a PDF file of an unedited manuscript that has been accepted for publication. As a service to our customers we are providing this early version of the manuscript. The manuscript will undergo copyediting, typesetting, and review of the resulting proof before it is published in its final form. Please note that during the production process errors may be discovered which could affect the content, and all legal disclaimers that apply to the journal pertain. 


\section{What do we learn from comparing hedonic scores and}

\section{willingness-to-pay data?}

3

* Corresponding author. INRA, UMR1324 Centre des Sciences du Goût et de l'Alimentation, 17 rue Sully, BP 86510, 21065 Dijon cedex, France Tel.: 33.3.80.69.30.76. Fax: 33.3.80.69.32.27. E-mail address: Sylvie.Issanchou@dijon.inra.fr 


\section{Abstract}

Consumer preferences for different variants of a given food product can be directly obtained with hedonic measurements or revealed with willingness-to-pay measurements. The aim of this paper is to present a comparison of the data collected using these two types of measurements on four data sets collected in our laboratory for different food products (bread, cooked ham, cheese and orange juice). This comparison was conducted at two levels (global and individual) and was based on two criteria: discrimination between variants and consistency in variant ranking. For the four data sets, the hedonic scores and reservation prices were collected for each participant in a 'full information' condition, i.e. in a condition where participants tasted each variant associated with extrinsic information. To reveal consumer willingness-to-pay, the BDM mechanism was used (Becker, DeGroot, \& Marschak, 1964), which consists in real sales at a random price. Aggregate results were similar for the two measurements. In addition, in two out of four studies, willingness-to-pay measurements led to slightly higher discrimination between variants than hedonic measurements. At the individual level, more inconsistencies were found. This result is in line with previous studies. Nevertheless, participants were more consistent concerning the most-liked variant than concerning the least-liked variant. Our results also showed that hedonic score distributions did not reveal any cut-off point below which consumers chose the no-purchase option; this cut-off point largely depended on individuals and products.

\section{Keywords}

Willingness-to-pay; Hedonic scores; Consumer preferences; Consistency;

Discrimination; Food valuation 


\section{$41 \quad$ Highlights}

1

2 3 4

42 We compare consumer hedonic scores to their willingness-to-pay from four studies.

43 At the group level, discrimination is similar for the two types of measurements.

44 At the group level, hedonic scores are consistent with willingness-to-pay.

45 The two types of measurements generate different individual rankings. 46 


\section{Introduction}

Hedonic or willingness-to-pay measurements can be used to assess consumer preferences for different variants of a given food product. Aiming both at predicting future choices, these two measurements result from answers to two specific questions: how much do consumers like a given product and which maximum price are they willing to pay for it (reservation price). Being different, these two questions may lead to different answers and to different conclusions. Therefore, given the high stakes linked to the segmentation of food markets and heterogeneity of consumers' behaviours, it is a major issue to better understand the differences between the two methods. Hedonic rating is widely used by sensory scientists, whereas economists usually rely on willingness-to-pay assessment to elicit preferences. This is probably why very few papers use both measurements and even fewer try to compare them.

Comparisons of different evaluation scales to assess preferences have been traditionally conducted by psychologists in the field of judgment and decision making (Hsee, Loewenstein, Blount \& Bazerman, 1999). One outstanding example is the "preference reversal" phenomenon, a well-known inconsistency which appears when subjects are asked to rate the attractiveness of different lotteries and also to give a price for each of them. Preference reversal was first reported by psychologists (Lichtenstein \& Slovic, 1971). The interest for the phenomenon has spread to experimental economics because it appeared as a major challenge to economic theory (Grether \& Plott, 1979). According to basic economic theory, differences in willingness-to-pay should reflect difference in preferences, and using hedonic rating or willingness-to-pay assessment should result in exactly the same ranking of alternatives. Thus, the reservation prices of each individual should be a monotonic transformation of the preferences expressed in their hedonic ratings (Melton, Huffman, Shogren \& Fox, 1996). The preference reversal controversy showed that this is not always the case, and that many factors 
can account for the difference. The main point is that the framing of the evaluation task matters. Joint or separate evaluation, wording of the questions, scales used to measure answers, all these factors focus individuals' attention on different characteristics, or dimensions of the alternatives to evaluate (Nowlis \& Simonson, 1997; Tversky, Sattath \& Slovic, 1988). Another point raised by economists (Grether \& Plott, 1979) is that incentives matter. Indicating hedonic scores on a scale yields no consequence for respondents. Conversely, offering a maximum buying price in a real sale is more involving because participants are actually committed to purchase a product at the end of the experiment. Consequently, hedonic measurement may be subject to the same kind of hypothetical bias which has been largely documented in economic valuation studies. Comparisons between hypothetical and non-hypothetical methods have shown that economic evaluations are largely overstated when elicited in a hypothetical context (List \& Gallet, 2001; Murphy, Allen, Stevens \& Weatherhead, 2005). To avoid this bias, many applied economists have turn to experimental auctions (Lusk \& Shogren, 2007), and more generally towards methods based on mechanisms that motivate participants to reveal as accurately and truthfully as possible their willingness-to-pay (WTP).

Without focusing mainly on the comparison of elicitation methods, some papers have used liking measurement jointly with experimental auctions. For example, Melton, Huffman, Shogren \& Fox (1996) found very good correspondence between both systems of preference elicitation with aggregate data. They underlined that discreteness in willingness-to-pay may explain a large part of the inconsistencies with hedonic scores (close scores may command the same WTP, and below some hedonic score threshold all WTPs are equal to zero). In a similar study of quality differentiated meat products, Umberger and Feuz (2004) also found a very significant relation between relative WTPs and relative taste ratings of paired samples of steaks. Roosen, Marette, Blanchemanche \& Verger (2007) compared hedonic ratings with 
choices between different quantities of alternative products, a measure actually close to relative willingness-to-pay. They found a strong correlation between liking scores and choices. The significant decrease of this correlation after releasing health information raised the issue of a possible contradiction between taste preference and purchase preference and highlight extrinsic information as one possible source of difference between hedonic scores and WTPs. This confirms that hedonic scores and WTPs may diverge in some cases, in particular when willingness-to-pay accounts for important attributes beyond sensory characteristics.

To our knowledge, three papers have further investigated the relationship between hedonic scores and WTPs: one study concerned champagne (Lange, Martin, Chabanet, Combris \& Issanchou, 2002), one concerned cookies, orange juice and chocolate bars (Noussair, Robin \& Ruffieux, 2004) and the third one concerned spelt (Stefani, Romano \& Cavicchi, 2006). In line with most of the previous papers, these three studies reveal an overall consistency in variant ranking between hedonic and willingness-to-pay results. Lange et al. (2002) found that external information (label) and sensory information (taste) have the same impact on the global product evaluation using hedonic scores or reservation prices. However, these authors observed a larger inter-individual heterogeneity in the relative weights of external and sensory information for hedonic scores compared to reservation prices. Stefani et al. (2006) observed as well more heterogeneity for hedonic scores than for WTPs. Investigating further the relationships between hedonic scores and WTPs, they finally suggested that in the presence of symbolic and affective components of the value, both measurements are not directly comparable because WTPs account for more value components than hedonic scores. Being the only one to explore the consistency between hedonic rating and WTP at the individual level, the paper by Noussair et al. (2004) goes deeper in the discussion of differences between the two measurements. Showing that some differences 
actually appear in individual rankings, the authors put forward two main sources of inconsistencies: first, they underlined that liking and purchase intentions are essentially different constructs, and second they suggested that auctions may not reveal the whole range of preferences in particular when the value of the good is low or possibly negative for some participants. However, individual inconsistencies did not prevent both methods to result in the same measure of preference intensity at the aggregate level.

The above issues and the potential importance of the two methods in product development are sufficient justification for collecting and comparing hedonic and willingnessto-pay data. Moreover, this analysis is relevant not only when actors in the food chain are interested in consumer acceptance of products based on their sensory characteristics, but also when they want to evaluate how consumers value product characteristics conveyed by a label giving information such as brand, origin, environmental impact, and health effects.

To contribute to the comparison of hedonic and willingness-to-pay data, we addressed three main questions. The first group of questions refers to the distributions of values collected with these two measurements: "Are the distributions of hedonic scores and reservation prices similar?", and more specifically, "What are the relationships between the distributions of hedonic scores and purchase decision?", i.e., "What are the distributions of hedonic scores for buyers compared to non-buyers?" The second question is "Do the two methods have the same capacity to discriminate different variants of a product?" At the individual level, one might wonder if the individual discrimination for one measure is related to the individual discrimination for the other. Finally, a third group of questions refers to the variant rankings. Consistency between hedonic scores and reservation prices can be examined through the similarity of the product hierarchy or at least the correspondence between the most- and least-liked products. Consistency can be examined at the group or individual level. 
To answer these three questions, we considered four data sets, each one concerning a

different type of food product: bread, cooked ham, cheese and orange juice. The next section presents in detail the selection of participants, the four data sets, the experimental design of each experiment and the data analysis that were performed. Section 3 presents the results which support the answers and discussions to our questions. Last, in section 4, we conclude and have a general discussion.

\section{Materials and methods}

\subsection{Participants}

For each study, a sample of consumers was recruited from the general population using different procedures: random selection in four shops of a bakery chain located in Dijon city and suburbs (bread); random dialling in Dijon city and suburbs (orange juice and cheese); and/or random selection from a panel of volunteer consumers in the PanelSens from the ChemoSens Platform (bread, cooked ham, cheese). Participants were selected if they regularly took part in food purchasing and consumed the products of interest in the study. If they agreed to participate, they were sent a letter that explained the main features of the experiment and provided details about the incentive method. Participants received a fee for their participation. Table 1 summarises the main characteristics of the participants for the four studies whose results were analysed in the present paper.

\section{[Insert Table 1 about here]}

Except for the cooked ham study, there was a higher proportion of women in all the studies, particularly in the bread study. Participants in the cheese study were older than those involved in the other ones, while participants in the orange juice study were younger. The monthly per capita income was significantly lower for the bread study participants, possibly 
because they bought their bread, at least occasionally, in shops of bakery chains that sell standard baguettes at low prices.

\subsection{Product variants}

In all studies, four product variants were tested (Table 2). For the bread study, the selected variants were four industrial French baguettes. Three of them had previously been sold on the market (Standard, Meunière and Cereal). The fourth was a new product named 'Healthy' (this bread offers potential health benefits). For the cooked ham study, there were two variants, one regular and one with two nutritional labels (low salt content and 'natural omega-3') for two brands (national brand and store brand). For the cheese study, there were two variants, one regular and one with a higher omega-3 content for two types of French cheese (Comté and Cantal). For the orange juice study, there was one pure juice and one nectar version for two brands (store/distributor brand and first price brand). It must be noted that, except for the cheese experiment where we had two subgroups (Comté and Cantal), all variants can be considered as close substitutes.

\section{[Insert Table 2 about here]}

\subsection{Experimental procedure}

\subsubsection{Overview of the designs}

189 The four studies were carried out at the National Institute for Agricultural Research in 190 Dijon (France) between spring 2005 and spring 2009. Each study focused on a different 191 product, namely, bread, cheese, cooked ham or orange juice.

The main characteristics of each study's design are presented in Table 3. For each 193 study, hedonic score and willingness-to-pay (WTP) measurements were obtained from the 
participants. The data shown here were collected under a 'full information' condition, in which participants tasted the sample with the product name for bread (standard, Meunière, Cereal, Healthy), and packaging with all mandatory information and nutritional claims for the three other products. For bread, hedonic measurements were collected in a first session, and then willingness-to-pay measurements were obtained two weeks ( $\mathrm{n}=92$ participants) or four weeks ( $\mathrm{n}=85$ participants) later. For cheese and cooked ham, the two tasks were performed separately within a single session, i.e., the four hedonic scores were collected first, and the four reservation prices were collected second. For orange juice, the two tasks were performed successively for each variant. A sequential monadic presentation was used for hedonic measurements in all studies, as was the case for the willingness-to-pay measurements in the orange juice study for which both measurements were collected in the same variant presentation. For the other studies, the four variants were presented simultaneously while participants were asked to give their reservation prices. For cheese and cooked ham, reservation prices were collected without actual re-tasting but based on tasting memory. In all cases, the presentation order of the four variants followed a Williams Latin square balanced for order and first-order carry-over effects. For a given consumer, this order was different for both measurements in the case of bread but was the same for cheese and cooked ham in order to help consumers to remind of their level of appreciation for each variant. Each session took place in a temperature controlled $\left(21 \pm 2^{\circ} \mathrm{C}\right)$ sensory room equipped with individual booths.

\section{[Insert Table 3 about here]}

\subsubsection{Hedonic measurements}

Participants answered the question "How much do you like this baguette [cooked ham, cheese, orange juice]?" on a linear scale, which was labelled "I don't like it at all" on the left side and "I like it very much" on the right side. The grades on the hedonic scales were 
converted into scores from 0 to 10 by measuring the distance between the left side of the scale and the participants' marks.

\subsubsection{Willingness-to-pay measurement}

The experimenter explained the principle of the BDM mechanism to the participants, using concrete examples. Participants were told that one product variant would be sold at a random price at the end of the session and, that individuals with a reservation price higher than the selling price would be committed to paying the random selling price. Then, participants were invited to sign a consent form and commitment to buy according to the principle previously explained. For each variant, participants answered the question "What is the maximum price you are ready to pay for this baguette [cooked ham, cheese, orange juice]?" They could choose a no-purchase option if they did not want to buy the item. In this case, the reservation price was considered as null. For each product variant, participants wrote down their reservation prices on a 'buying form' for orange juice and used a computer for the other studies. Participants were told that at the end of the session, they will be asked to randomly select one variant out of all the products they had evaluated. This procedure was used to maintain the same level of involvement for all variants and to ensure that participants did not have to buy an excess of products, which might have induced them to reduce their reservation prices. Each participant randomly drew one token indicating a selling price. Participants were told that prices on the tokens were distributed according to the selling prices of each product on the Dijon market. However, the market prices were never communicated to the participants. The price written on the token was compared to the reservation price given 242 by the participant. If the participant's reservation price submitted for the selected variant was 243 equal to or higher than the price on the drawn token, the participant had to buy the product variant at the price on the token. If the participant's reservation price was lower than the price 
on the token, the participant had no opportunity to purchase the item. At the end of the session, participants could ask to examine the bag of price tokens.

\subsection{Data Analysis}

All statistical analyses were performed for each study and carried out with SAS/STAT ${ }^{\circledR}$ software, version 9.1 (SAS Institute Inc., Cary, NC, USA, 2002-2003).

\subsubsection{Comparison of the types of measurements at the global level}

Firstly, the distributions of hedonic scores and reservation prices were examined. Secondly, in order to compare discrimination between the two types of measurements at the global level, an analysis of variance (ANOVA) was performed on each data set, and $F$ values were compared. The ANOVA procedure was used according to the following model:

hedonic $($ reservation price $)=$ participant + variant + error .

When the ANOVA revealed a significant effect $(p<0.05)$, least-square means and the 95\% confidence intervals were calculated, and $t$-tests were performed.

Finally, consistency between the hedonic scores and reservation prices for the four variants and each study was examined by calculating Kendall correlation coefficients between mean values.

\subsubsection{Comparison of the types of measurements at the individual level}

264 In order to compare discrimination between the two types of measurements at the 265 individual level the coefficients of variation (CV) were calculated for each participant and 266 each type of measurement, then, the Kendall correlation between the two series of CV was 267 calculated for each product.

In order to examine consistency at the individual level, several indices were calculated.

The same approach as the one used by Noussair et al., 2004) was adopted to declare a 
participant as consistent. First, for each participant, the Kendall correlation coefficient

271 between the hedonic scores and reservation prices was calculated in order to examine the consistency for all variants. Then, consistency was assessed for the most- and least-liked variants. The first criterion, called 'strict consistency', for all variants corresponds to the following situation: for any couple of variants, if the hedonic score [variant A] is higher than the hedonic score [variant B], then the reservation price [variant A] should be higher than the reservation price [variant B]. This equation gives a Kendall correlation equal to 1 . The second criterion, 'Weak consistency', for all variants, is less severe; it corresponds to the following situation: for any couple of variants, if the hedonic score [variant A] is higher than or equal to the hedonic score [variant $\mathrm{B}$ ], then the reservation price [variant $\mathrm{A}$ ] should be higher than or equal to the reservation price [variant B]. In the case of four variants, this equation gives Kendall correlation coefficient above 0.70 and lower than 1 . Moreover, consistency on the most-liked and the most-disliked variants were also examined.

The impact of several individual characteristics (e.g. sex, age, income) on the Kendall correlation between the coefficients of variation for hedonic scores and the coefficients of variation for reservation prices, as well as on the Kendall correlation between variant rankings was examined. No significant effect appeared and consequently these results are not reported.

\section{Results and discussion}

The comparison between hedonic scores and reservation prices is presented below at both the global and individual levels. At the global level, a descriptive analysis of the distributions of hedonic scores and reservation prices was performed.

\subsection{Global level}

\subsubsection{Comparison of the distributions of hedonic scores and reservation prices}


When comparing the distributions according to the method, it was observed that each

study yielded a high frequency of null reservation prices (corresponding to the no-purchase option) but an extremely low frequency of null hedonic scores (Fig. 1). Additionally, the distributions of hedonic scores, but not the reservation prices, for bread and cheese are skewed to the right. These observations are in agreement with previous data (Lange et al., 2002) on champagne, a product with a high monetary value. These authors suggested that a greater commitment in the case of willingness-to-pay measurements compared to hedonic measurements may explain this difference. The present results illustrate that even with a low monetary value product, giving a high hedonic score does not mean to be willing to purchase the product at a high price. It is also important to note that despite the experimental situation and the fee given to the participants, the reservation prices were rarely lower or higher than the market prices for the same product category. As demonstrated by Harrison, Harstad \& Rutström, (2004), observed reservation prices are censored by market prices. In the case of orange juice, apart from the null reservation prices, the reservation price distribution and the hedonic score distributions are very flat. Therefore, both measurements revealed great individual variability in consumer reactions in this study.

\section{[Insert Figure 1 about here]}

A comparison of the hedonic score distributions for buyers and non-buyers (Fig. 2) yields no clear cut-off point below which consumers chose the no-purchase option. However, the mean hedonic scores corresponding to no-purchase decisions are not surprisingly lower than for purchase decisions. Nevertheless, the mean scores for no-purchase decisions differ according to the product. For bread and cheese, the percentage of non-buyers started to decrease above a hedonic score of 6 while for cooked ham, this percentage started to decrease above a hedonic score of 5 , and for orange juice above a hedonic score of 2 . Thus, it seems that consumers are more ready to accept a least-liked variant for orange juice than for the 
other products, particularly for bread and cheese. The results for orange juice are in agreement with the results obtained by Lange et al. (1999), who examined the role of hedonic scores and prices in purchase behaviour when the consumers were placed in a situation of choice under economical constraint. This study found that consumers could choose their least-liked product. One possible explanation proposed by these authors could also apply here: "non single consumers could have ordered products not only for themselves but for the whole family and thus could have chosen products depending on the family members' preferences". The results for bread could be explained by bread's important social and cultural role for French consumers (Kaplan, 2002). The effect of socio-cultural values on French consumers can also apply to cheese (Roberts \& Micken, 1996). For these two types of products, a higher proportion of consumers must really like the product to be willing to purchase it.

\section{[Insert Figure 2 about here]}

\subsubsection{Discrimination between variants and consistency between variant rankings}

The results show a significant variant effect for all products (all $p$ values $<0.0001$ ) and similar $F$ values for both methods (Fig. 3).

\section{[Insert Figure 3 about here]}

of the measurement. For orange juice and cooked ham, the same number of groups was obtained regardless of the measurement. For bread and cheese, three groups of variants were obtained for the hedonic scores and four for the reservation prices. Therefore, the willingnessto-pay measurement appears slightly more discriminant than the hedonic measurement. The difference could be related to the different way consumer responses were collected. In our hedonic measurements, consumers expressed their degree of liking on a linear scale, i.e., a 
visual analogic scale. Therefore, they are not aware (except for the anchors) of the exact numerical value deduced from their evaluation. Conversely, for willingness-to-pay measurements, consumers directly gave their reservation price and are thus conscious of the numerical values and more able to express small differences in the reservation prices between variants. Nevertheless, the differences between both measurements in terms of variant discrimination are minor, and we can conclude that there is a relatively high agreement at the global panel level for giving a high hedonic score and a high reservation price.

Thus, our results that show a good overall consistency between hedonic scores and reservation prices are in agreement with results from previous studies (Lange et al., 2002; Noussair et al., 2004; Stefani et al., 2006). In fact, all these studies revealed the same ordering of the different variants for both measurements. The main difference is observed with data on champagne (Lange et al., 2002). In the same information condition (bottle and tasting), these authors observed a higher $F$ value for reservation prices than for hedonic scores (data not shown). This difference could be due to champagne's high social value and the importance of brand reputation in particular on monetary value.

\subsection{Individual level}

\subsubsection{Discrimination between variants}

The Kendall correlations calculated between individual coefficients of variation (CV)

obtained for hedonic scores and reservation prices were significant for all studies except for the bread study (Table 4). This finding means than for three out of the four studies, the level of individual discrimination for hedonic scores is related to the level of individual discrimination for reservation prices. In the case of bread, participants could have liked the variants differently but were not ready to buy them at different prices. This is particularly noticeable as bread was, among the four products studied, the one with the lowest unitary 
price. However, this behaviour could be related to the fact that this product is bought almost daily and has a stable price, which may have been used as a reference regardless of the perceived quality of the product.

\section{[Insert Table 4 about here]}

\subsubsection{Consistency of individual rankings}

The percentage of participants who satisfied the two consistency criteria is presented for each data set in Table 5. This table shows that there were discrepancies between the hedonic scores and reservation prices of individual participants. Moreover, a significant chi-square is observed $\left(\chi^{2}=23.5, p<.0001\right)$ for the weak consistency criterion, which reveals that the percentages of participants who satisfied this criterion differ according to product. This significant chi-square is due to the orange juice data, where a higher percentage of weak consistency is observed; the chi-square is no longer significant $\left(\chi^{2}=5.1, \mathrm{p}=0.08\right)$ when the orange juice data set was excluded. This better result for orange juice can be explained by the design; as noted previously, for each variant presented in this experiment, the reservation price was collected immediately after the hedonic score, whereas in the other experiments, the four hedonic scores were collected, then participants gave their four reservation prices. The effect of the experimental conditions is confounded with the product effect, but this hypothesis seems plausible. On average, in the four data sets, only $17.6 \%$ of the participants had the same strict ordering of the four variants for both methods. The average consistency between the two measures increases to $50.7 \%$ if ex-æquo on one of the methods is permitted. In their study on orange juice, Noussair et al. (2004) obtained a higher level (31.5\%) of strict consistency for a similar product and higher levels for both strict and weak consistency than our average values. This discrepancy could be explained by the lower number of variants in 
their study (three instead of four). Another possible explanation is that in their experiment, the different variants were tasted without any extrinsic information. Extrinsic information, such as brand, could modify the economic value attributed to a variant due to the influence of the market price, possibly because participants do not give the same importance to the sensory and non-sensory properties of each variant when assigning a hedonic score and when stating a reservation price. For example, a participant could like a nectar version more than a pure juice version but does not want to give a higher reservation price for the nectar than for the pure juice if $s /$ he is aware that nectar is made of juice with water and sugar added.

\section{[Insert Table 5 about here]}

\subsubsection{Consistency on the most-liked and the most-disliked variants}

We further explored the relationships between the two measurements by looking at the agreement level for the most-liked (most-valued) and the least-liked (least-valued) variants. Concerning the ranking of the four variants, we defined strict and weak consistency criteria. The strict preference consistency corresponds to the case in which participants gave the highest score and the highest reservation price to the same variant. The weak preference consistency corresponds to the case where there were ex-æquo values for one method.

The percentage of participants who satisfied these two consistency criteria is presented for each data set in Table 6.

\section{[Insert Table 6 about here]}


criterion, this result is only true for bread and orange juice studies. The greater difference between strict consistency and weak consistency for the least-liked variants than for the mostliked variants can be explained by a tendency of participants to give a zero reservation price not just for the least-liked variant. In fact, for the orange juice, cheese and cooked ham studies where the difference between strict consistency and weak consistency for the least-liked variants was particularly high, we observed $39.5,30.8$ and $21.4 \%$ of participants, respectively, who did not want to purchase variants that they had ranked at the fourth and third hedonic positions.

\section{General discussion and conclusion}

In accordance with previous studies, aggregate results are similar for the two measurements. In addition, our willingness-to-pay measurements led to slightly higher discrimination between variants in two out of four studies. One reason for that difference is the fact that hedonic measurements use an unstructured analogic scale (the position on a bar), whereas willingness-to-pay is directly measured in Euros, which may enable a higher precision of the latter. This point does not seem to have received much attention yet. It can be pointed out that when two variants of a product were significantly different for willingness-topay measurements but not for hedonic measurements, the 'healthy' variants (B4 for bread and C2 for cheese) were less valued than the standard variants.

At the individual level, we found more inconsistencies, which again is in line with previous studies. The two types of measurements generate different individual rankings, and there is no way to identify whether this discrepancy is due to the type of measurement or to a change in participant preferences. In fact, several authors have shown that, even when using the same type of measurement, participant preferences can change even within a session. For example, when participants were asked to indicate their preferred variant among two out of 
five different orange juices, which they had just previously rated on a linear hedonic scale, only 66\% were consistent (Cordelle, Lange \& Schlich, 2004). Lévy and Köster (1999) obtained similar results (58\% consistency) when participants chose their preferred variants among three soft drinks previously rated on a 9-point hedonic scale. This volatility of preferences is a well-acknowledged fact among sensory scientists (Köster, 1991; Köster, 2003; Köster, Couronne, Léon, Levy \& Marcelino, 2003). This low level of consistency observed could also be explained by the fact that, except for the cheese experiment where we had two subgroups (Comté and Cantal), our variants can be considered as close substitutes. Nevertheless, we did not observe a higher consistency for cheese compared to the three other products. However, despite these individual inconsistencies, between hedonic scores and reservation prices, on the rankings of all variants, it appears that participants were more consistent on the most-liked variant than on the least-liked.

As mentioned in the introduction the two methods refer to different constructs (i.e., hedonic value and economic value). Hedonic scores are supposed to reflect private values. However, when hedonic scores are collected in an informed condition (i.e., tasting with external information) they could be influenced by a desirability bias due to the hypothetical situation, in particular when information is related to nutritional characteristics with potential health benefits. This possibility of such a bias has been previously underlined by several authors (e.g., Daillant-Spinnler \& Issanchou, 1995; Lundgren, 1981). On the contrary, reservation prices are supposed to be less influenced by a desirability bias due to the nonhypothetical situation. This could explain the greater discrimination between standard and healthy variants for bread and cheese. Nevertheless, different factors could impact reservation prices. Firstly, as nicely demonstrated by Muller and Ruffieux (2011) reservation prices do not exclusively correspond to private values but are partly influenced by common value (market price). Secondly, budget constraints could influence reservation prices. Nevertheless, 
in the present experiment individual consistency, measured by Kendall correlation, did not differ according income per capita (data not shown). Thirdly, inconsistency could be due to the fact that hedonic scores are not supposed to be influenced by consumer's need of the product whereas it could be the case for reservation prices.

In spite of inconsistencies at the individual level, both methods lead to very similar conclusions when aggregated data are considered. Our results also revealed that there was no clear cut-off point below which consumers chose the no-purchase option; this cut-off largely depends on individuals and on products. Further research that focuses on specific points of the protocol (numeric scales used for both methods, simultaneous or sequential evaluation of the different variants, presence of external information such as a brand, a nutritional label, use of a common market value as a reference price) may contribute to a deeper understanding of the inconsistencies at the level of individual participants.

In conclusion, as previously underlined by Lange et al. (2002), willingness-to-pay measurement seems to be a relevant approach to reveal the true individual value of a product when external information is provided. This seems particularly important when information is about product healthiness as in such a case hedonic measurement may suffer of a desirability bias.

\section{Acknowledgements}



520

016264); the information in this document reflects the authors' views only, and the Community is not liable for any possible use of the information contained therein. The authors would like to thank Fabienne Bouillot and Christophe Martin (ChemoSens) for their critical logistical help during the experiments.

\section{References}

500 Cordelle, S., Lange, C., \& Schlich, P. (2004). On the consistency of liking scores: Insights 501 from a study including 917 consumers from 10 to 80 years old. Food Quality and Preference, $502 \quad 15,831-841$

503 Daillant-Spinnler, B., \& Issanchou, S. (1995). Influence of label and location of testing on acceptability of cream cheese varying in fat content. Appetite, 24, 101-106.

Grether, D. M., \& Plott, C. R. (1979). Economic theory of choice and the preference reversal phenomenon. The American Economic Review, 69, 623-638.

Harrison, G. W., Harstad, R. M., \& Rutström, E. E. (2004). Experimental methods and elicitation of values. Experimental Economics, 7, 123-140.

Hsee, C. K., Loewenstein, G. F., Blount, S., \& Bazerman, M. H. (1999). Preference reversals between joint and separate evaluations of options: A review and theoretical analysis. Psychological Bulletin, 125, 576-590.

Kaplan, S. L. (2002). Le retour du bon pain. Une histoire contemporaine du pain, de ses techniques et de ses hommes. Paris (FRA): Editions Perrin.

514 Köster, E. P. (1991). The dynamics of consumer preferences and aversions. In Food 515 Ingredients Asia Conference Proceedings 1991, Expoconsult, Maarssen, The Netherlands.

516 Köster, E. P. (2003). The psychology of food choice: some often encountered fallacies. Food 517 Quality and Preference, 14, 359-373.

518 Köster, E. P., Couronne, T., Léon, F., Levy, C., \& Marcelino, A. S. (2003). Repeatability in hedonic sensory measurement: a conceptual exploration. Food Quality and Preference, 14, $165-176$ 
Lange, C., Martin, C., Chabanet, C., Combris, P., \& Issanchou, S. (2002). Impact of the information provided to consumers on their willingness to pay for Champagne: comparison with hedonic scores. Food Quality and Preference, 13, 597-608.

Lange, C., Rousseau, F., \& Issanchou, S. (1999). Expectation, liking and purchase behaviour under economical constraint. Food Quality and Preference, 10, 31-39.

Lévy, C. M., \& Köster, E. P. (1999). The relevance of initial hedonic judgements in the prediction of subtle food choices. Food Quality and Preference, 10, 185-200.

Lichtenstein, S., \& Slovic, P. (1971). Reversals of preference between bids and choices in gambling decisions. Journal of Experimental Psychology, 89, 46-55.

List, J. A., \& Gallet, C. A. (2001). What experimental protocol influence disparities between actual and hypothetical stated values? Environmental and Resource Economics, 20, 241-254.

Lundgren, B. (1981). Effect of nutritional information on consumer responses. In J. Solms, \& R. L. Hall (Eds), Criteria of food acceptance, (pp. 27-33). Zurich: Forster-Verlag AG.

Lusk, J. L., \& Shogren, J. F. (2007). Experimental auctions. Methods and applications in economic and marketing research. Cambridge: Cambridge University Press.

Melton, B. E., Huffman, W. E., Shogren, J. F., \& Fox, J. A. (1996). Consumer preferences for fresh food items with multiple quality attributes: Evidence from an experimental auction of pork chops. American Journal of Agricultural Economics, 78, 916-923.

Muller, L., \& Ruffieux, B. (2011). Do price-tags influence consumers' willingness to pay? On the external validity of using auctions for measuring value. Experimental Economics, 14, 181202.

542 Murphy, J. J., Allen, P. G., Stevens, T. H., \& Weatherhead, D. (2005). A meta-analysis of 543 hypothetical bias in stated preference valuation. Environmental and Resource Economics, 30, $544 \quad 313-325$.

545 Noussair, C., Robin, S., \& Ruffieux, B. (2004). A comparison of hedonic rating and demand546 revealing auctions. Food Quality and Preference, 15, 393-402. 
547 Nowlis, S. M., \& Simonson, I. (1997). Attribute-Task Compatibility as a Determinant of

1

Consumer Preference Reversals. Journal of Marketing Research, 34, 205-218.

Roberts, S. D., \& Micken, K. S. (1996). Le fromage as life: French attitudes and behavior toward cheese. Advances in Consumer Research Volume, 23, 111-119.

Roosen, J., Marette, S., Blanchemanche, S., \& Verger, P. (2007). The effect of product health information on liking and choice. Food Quality and Preference, 18, 759-770.

553 Stefani, G., Romano, D., \& Cavicchi, A. (2006). Consumer expectations, liking and 554 willingness to pay for specialty foods: Do sensory characteristics tell the whole story? Food 555 Quality and Preference, 17, 53-62.

556 Tversky, A., Sattath, S., \& Slovic, P. (1988). Contingent weighting in judgment and choice. 557 Psychological Review, 95, 371-384.

558 Umberger, W. J., \& Feuz, D. M. (2004). The usefulness of experimental auctions in 559 determining consumers' willingness-to-pay for quality-differentiated products. Review of 560 Agricultural Economics, 26, 170-185. 
563

Tables

564 Table 1

565 Characteristics of the participants in each study

566

\begin{tabular}{|c|c|c|c|c|c|}
\hline & \multirow[b]{4}{*}{$\mathrm{n}$} & \multicolumn{4}{|c|}{ Study } \\
\hline & & & & Cooked & Orange \\
\hline & & Bread & Cheese & ham & juice \\
\hline & & 177 & 195 & 126 & 86 \\
\hline \multirow[t]{2}{*}{ Gender } & Male & 58 & 84 & 66 & 31 \\
\hline & Female & 119 & 111 & 60 & 55 \\
\hline \multirow[t]{4}{*}{ Age } & Mean & 42.2 & 50.0 & 44.8 & 38.0 \\
\hline & Min & 19.0 & 21.0 & 25.0 & 16.0 \\
\hline & Max & 81.0 & 81.0 & 66.0 & 81.0 \\
\hline & SD & 16.2 & 14.4 & 12.8 & 14.7 \\
\hline \multirow[t]{4}{*}{ Income $^{a}$} & Mean & 1003.8 & 1256.9 & 1293.3 & 1216.6 \\
\hline & Min & 0 & 330.0 & 514.3 & 0.0 \\
\hline & Max & 2520.0 & 3480.0 & 4020.0 & 9500.0 \\
\hline & SD & 575.9 & 572.3 & 596.5 & 1167.6 \\
\hline Household & 1 & 33 & 29 & 18 & 18 \\
\hline \multirow[t]{3}{*}{ size } & 2 & 74 & 86 & 44 & 27 \\
\hline & $3-4$ & 51 & 66 & 52 & 32 \\
\hline & $>4$ & 16 & 14 & 3 & 9 \\
\hline
\end{tabular}

${ }^{\mathrm{a}}$ Monthly income per capita (in $€$ ) 
Table 2

Characteristics of the product variants in each study

\begin{tabular}{lllll}
\hline Study & Variant & Brand & Label & Market price (€) \\
\hline Cooked Ham & H1 & National & $/$ & 2.67 \\
& H2 & National & Low salt content and 'natural $\omega-3$ ' & 2.78 \\
& H3 & Store & $/$ & 2.14 \\
& H4 & Store & Low salt content and 'natural $\omega-3$ ' & 3.10 \\
\hline Cheese & C1 & AOP & Comté & 2.00 \\
& C2 & AOP & Comté 'Higher $\omega-3$ content' & 2.25 \\
& C3 & AOP & Cantal & Test product ${ }^{\mathrm{a}}$ \\
& C4 & AOP & Cantal 'Higher $\omega-3$ content' & Test product ${ }^{\mathrm{a}}$ \\
\hline Bread & B1 & National & Standard & 0.64 \\
& B2 & National & Meunière & 0.87 \\
& B3 & National & Cereal & 1.06 \\
& B4 & Experimental & Healthy & 0.95 \\
\hline Orange juice & J1 & Lowest-price & Nectar & 0.31 \\
& J2 & Store & Nectar & 1.00 \\
& J3 & Lowest-price & Pure juice & 0.63 \\
& J4 & Store & Pure juice & 1.51 \\
\hline
\end{tabular}

${ }^{\mathrm{a}}$ Test product not sold on the market, produced by INRA - URH Theix 
573

Table 3

574 Main characteristics of each study's design

\begin{tabular}{|c|c|c|c|}
\hline \multirow[b]{2}{*}{ Study } & \multicolumn{2}{|c|}{ (Measure * Variant) order } & \multirow{2}{*}{$\begin{array}{l}\text { Variant order }{ }^{\mathrm{a}} \text { for hedonic scores } \\
\text { (Hedo) and willingness-to-pay (WTP) }\end{array}$} \\
\hline & Step 1 & Step 2 & \\
\hline Bread & Hedo $* 4$ variants & WTP $* 4$ variants & Different per parti \\
\hline Cheese & Hedo $* 4$ variants & WTP $* 4$ variants & Same per participant \\
\hline Cooked ham & Hedo * 4 variants & WTP * 4 variants & Same per participant \\
\hline Orange juice & \multicolumn{2}{|c|}{$\begin{array}{c}\text { Step } 1 \& 2 \text { combined: } \\
(\text { Hedo + WTP }) * 4 \text { variants }\end{array}$} & Same per participant \\
\hline
\end{tabular}

${ }^{\mathrm{a}}$ All orders were balanced (Williams Latin squares) 
577

2 3 4

Table 4

578 Kendall correlations between individual coefficients of variation for hedonic scores and for reservation prices in each study

\begin{tabular}{llll}
\hline Study & $\begin{array}{l}\text { Mean value of } \\
\text { Kendall correlation }\end{array}$ & $p$ value & Missing values $^{\mathrm{a}}$ \\
\hline Bread & 0.05 & 0.37 & 4 \\
Cheese & 0.28 & $<0.0001$ & 2 \\
Cooked ham & 0.31 & $<0.0001$ & 0 \\
Orange juice & 0.28 & 0.0002 & 3 \\
\hline
\end{tabular}

$580{ }^{a}$ Missing values due to no purchase for all variants 
Table 5 4 5 6 7 8 9 10

Percentages of participants satisfying the strict and weak consistency criteria in each study

\begin{tabular}{lll}
\hline Study & Strict consistency $(\%)$ & Weak consistency (\%) \\
\hline Bread & 20.9 & 40.7 \\
Cheese & 13.8 & 52.3 \\
Cooked ham & 17.5 & 47.6 \\
Orange juice & 19.8 & 72.1 \\
\hline Pooled data & 17.6 & 50.7 \\
\hline
\end{tabular}


Table 6 3 4

Percentages of participants ${ }^{\mathrm{a}}$ satisfying the strict and weak consistency criteria for the most-

liked and most-disliked variants in each study

\begin{tabular}{|c|c|c|c|c|}
\hline \multirow[b]{2}{*}{ Study } & \multicolumn{2}{|c|}{ Most-liked variant } & \multicolumn{2}{|c|}{ Most-disliked variant } \\
\hline & Strict & Weak & Strict & Weak \\
\hline & & & & \\
\hline Cheese & $500 \%$ & $703 \%$ & $303 \%$ & $697 \%$ \\
\hline Cooked ham & $57.1 \%$ & $67.5 \%$ & $34.9 \%$ & $69.8 \%$ \\
\hline Orange juice & $68.6 \%$ & $81.4 \%$ & & $72.1 \%$ \\
\hline
\end{tabular}

$588{ }^{a}$ Excluding participants with to no or only one purchase 
List of figures and captions

1 591

3

Fig. 1. Distributions of hedonic scores and reservation prices in each study. The vertical lines indicate the extreme values of price on the market. The arrow indicates the average market price

Fig. 2. Distributions of hedonic scores for the buyers and non-buyers in each study. Light grey $=$ non-buyers; dark grey $=$ buyers .

Fig. 3. Averages of the hedonic scores and reservation prices for each product variant. 
601

1

2602

3603

4

5

6

7

8

9

10

11

12

13

14

15

16

17

18

19

20

21

22

23

24

25

26

27

28

29

30

31

32

33

34

35

36

37

38

39

40

41

42

43

44

45

46

47

48

49

50

51

52

53

54

55

56

57

58

59

60

61

62

63

64

65
Fig. 1

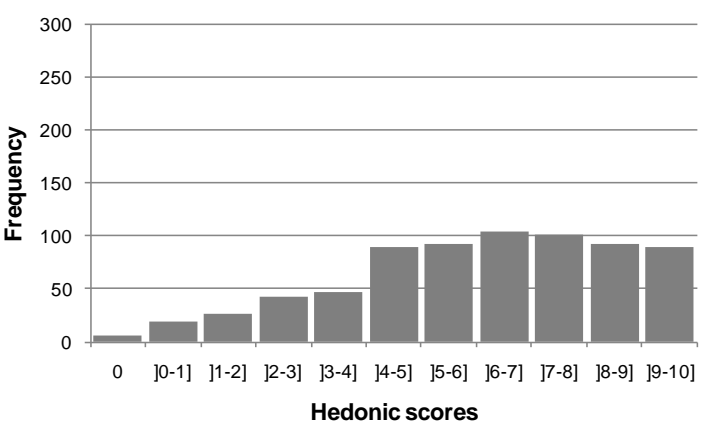

Bread

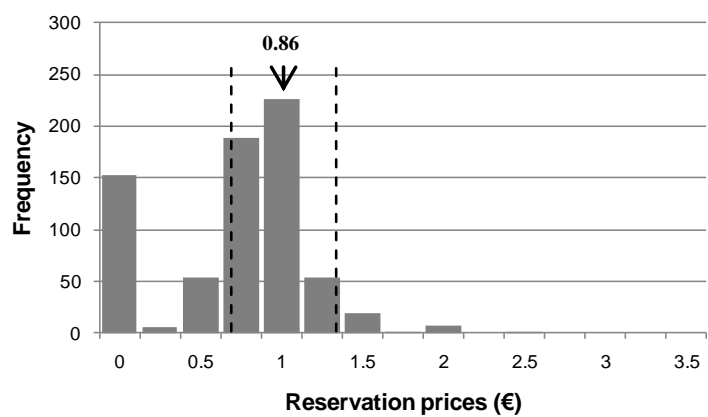

\section{Cheese}

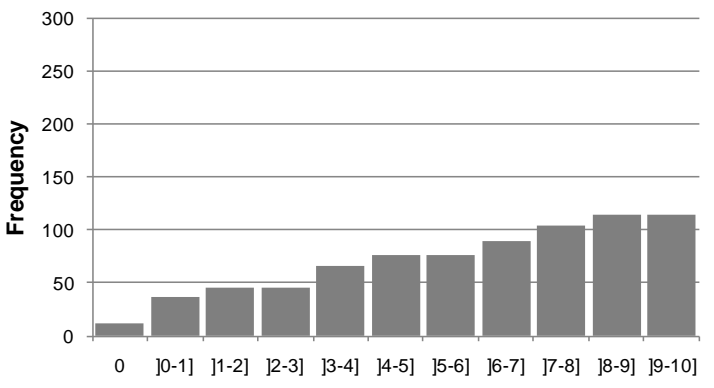

Hedonic scores

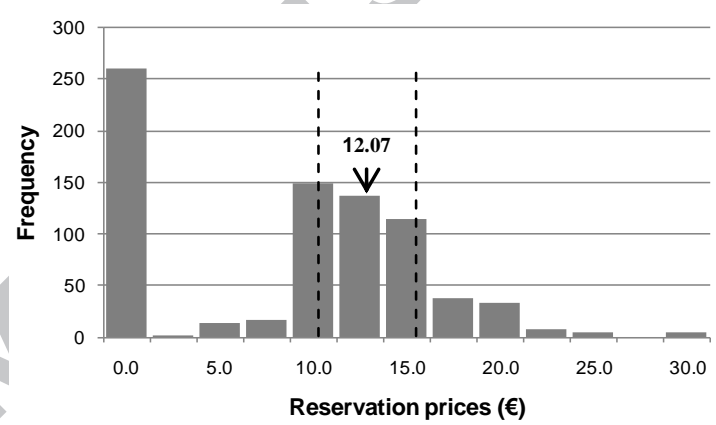

\section{Cooked ham}
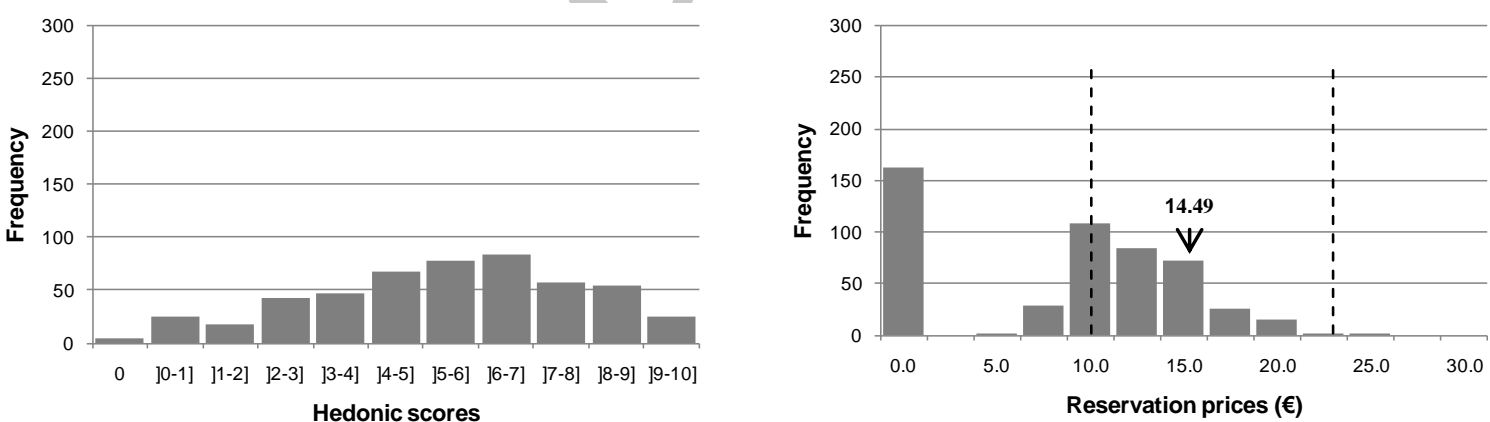

Hedonic scores

\section{Orange juice}
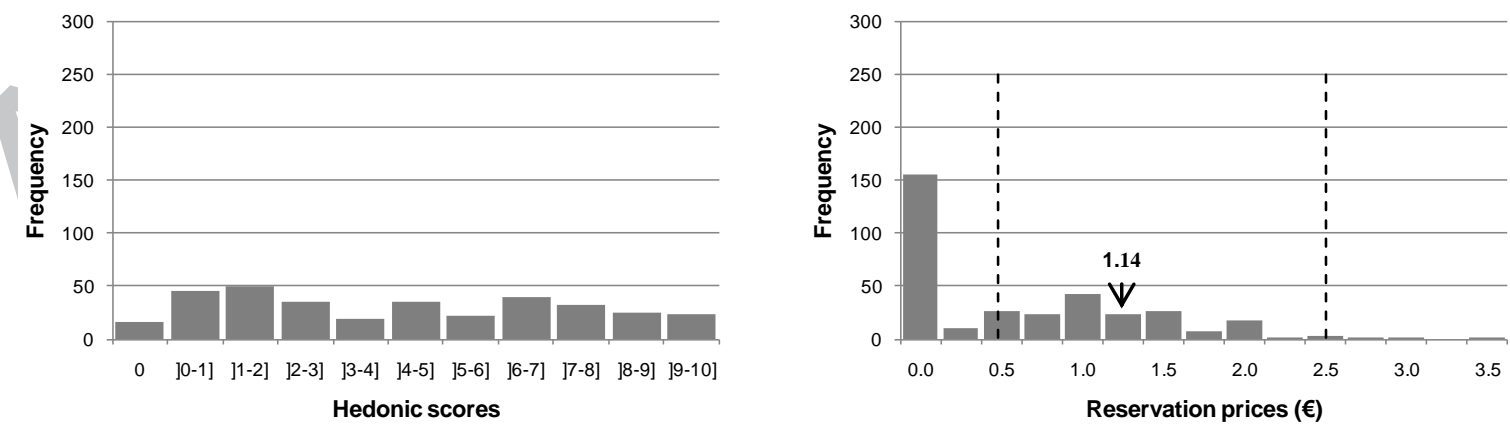

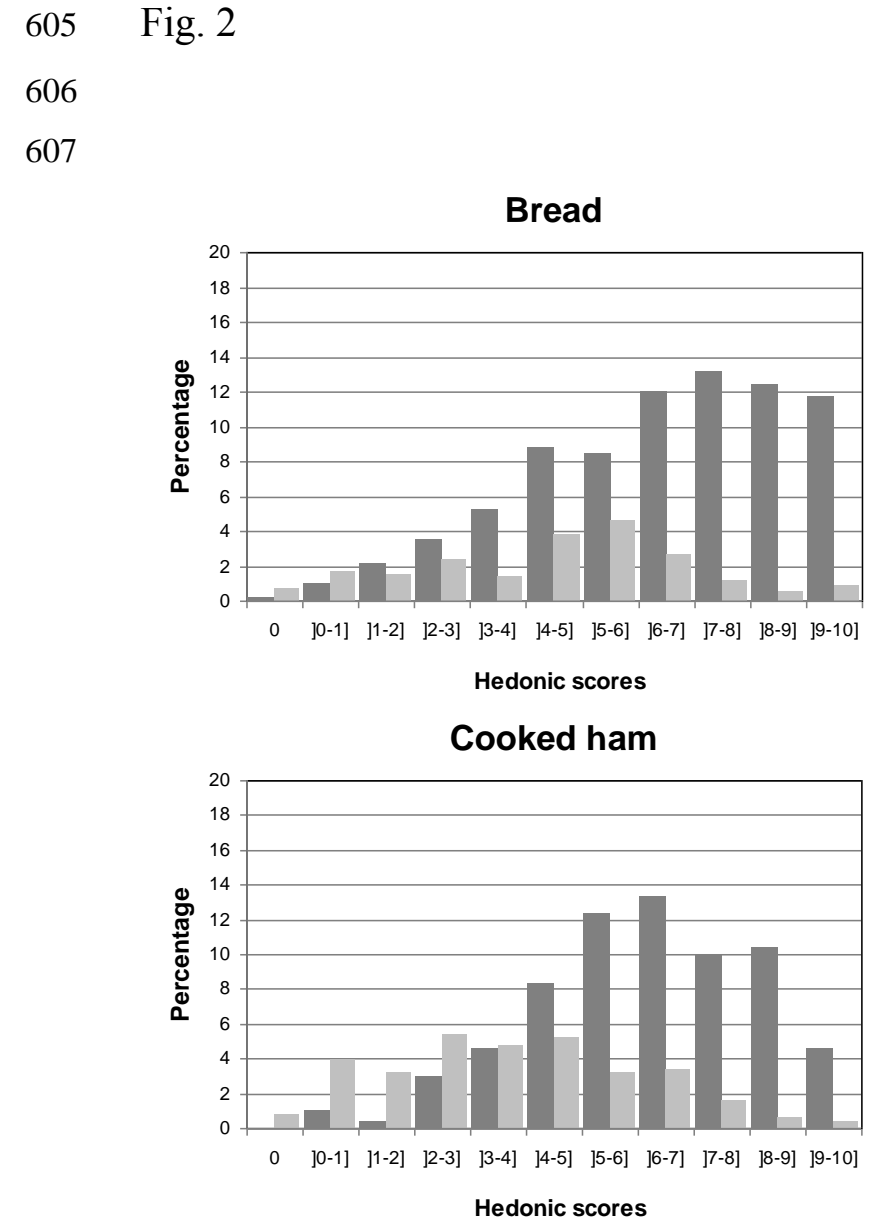
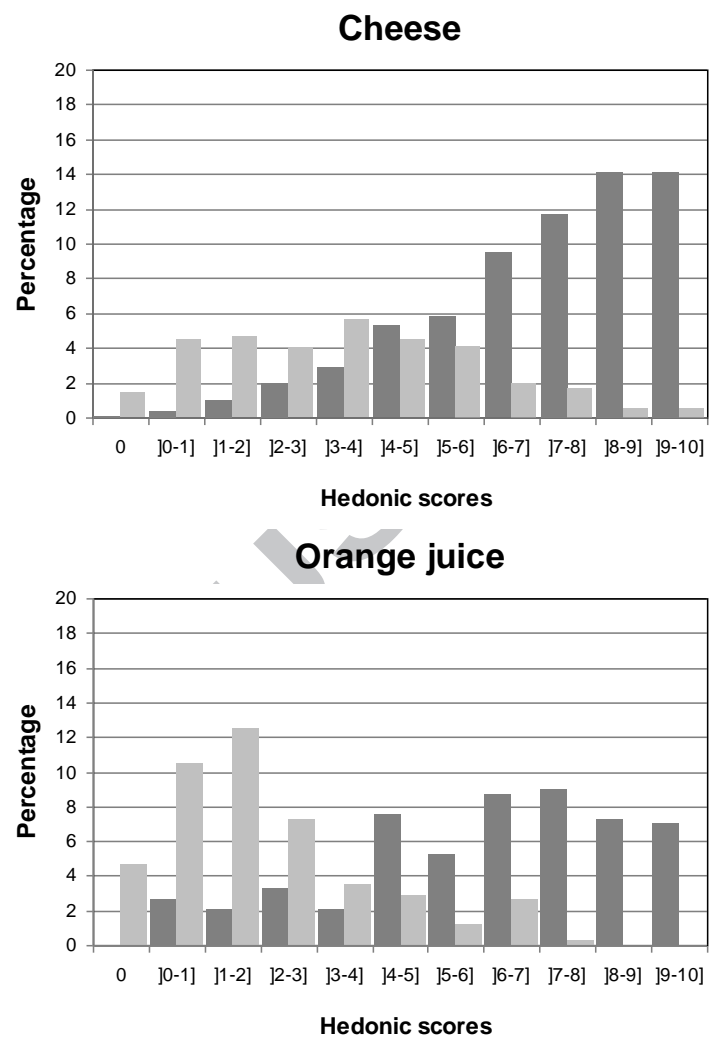
Fig. 3.

Bread
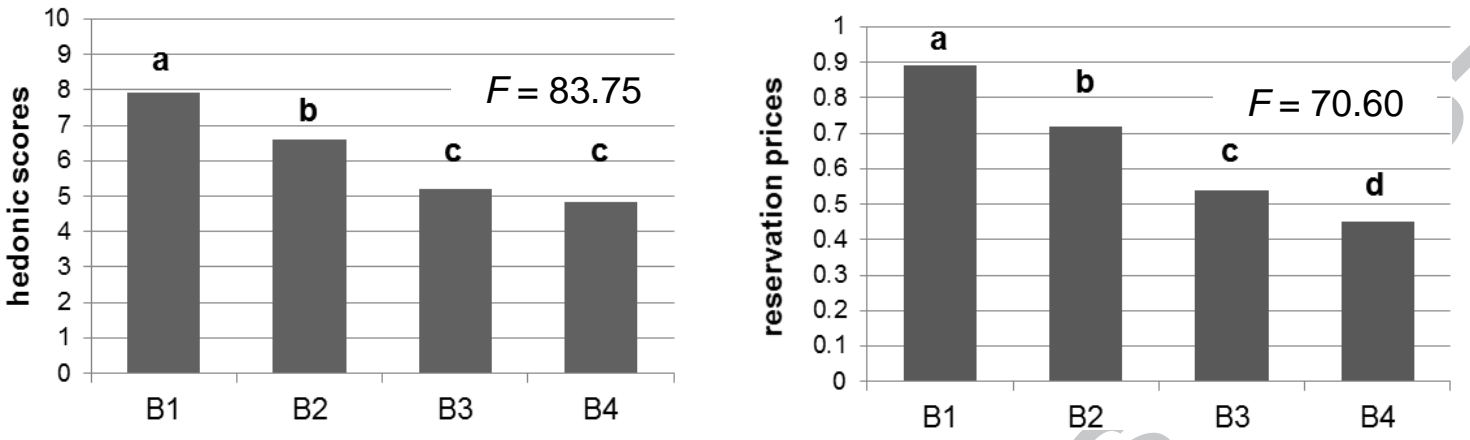

Cheese
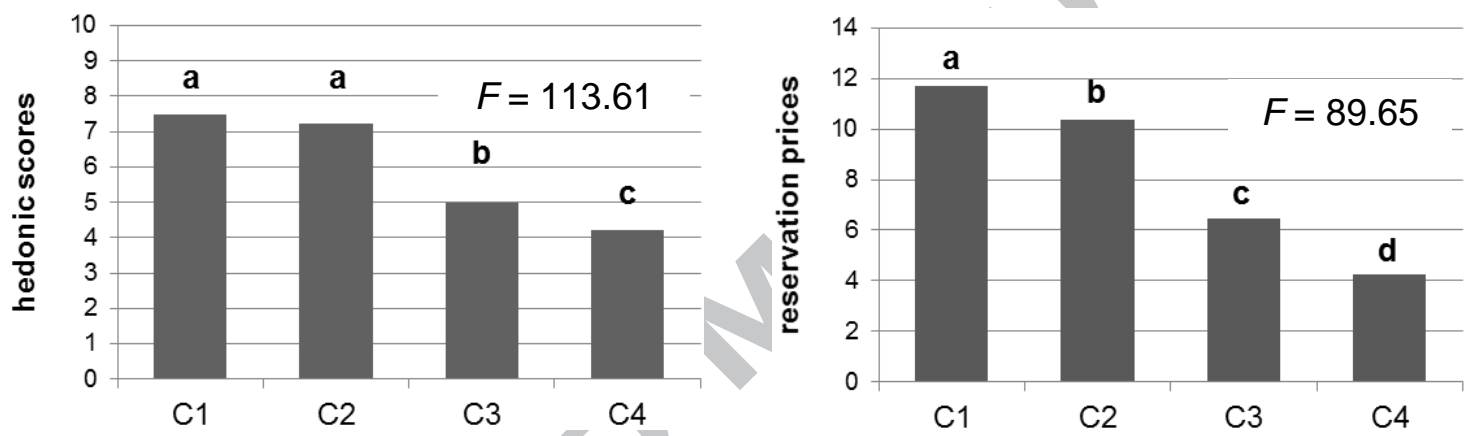

Cooked ham
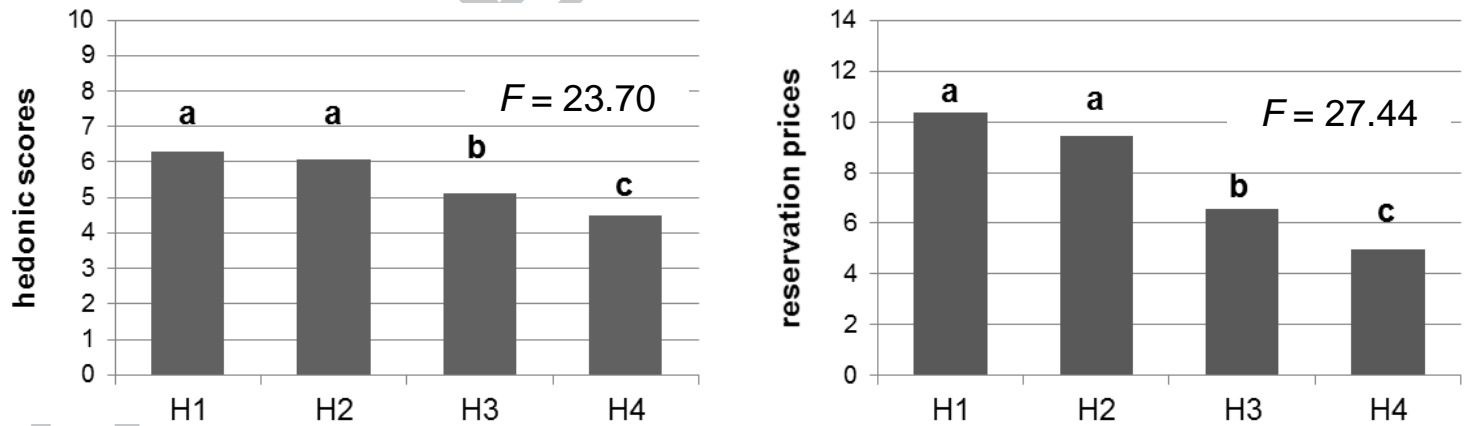

Orange juice
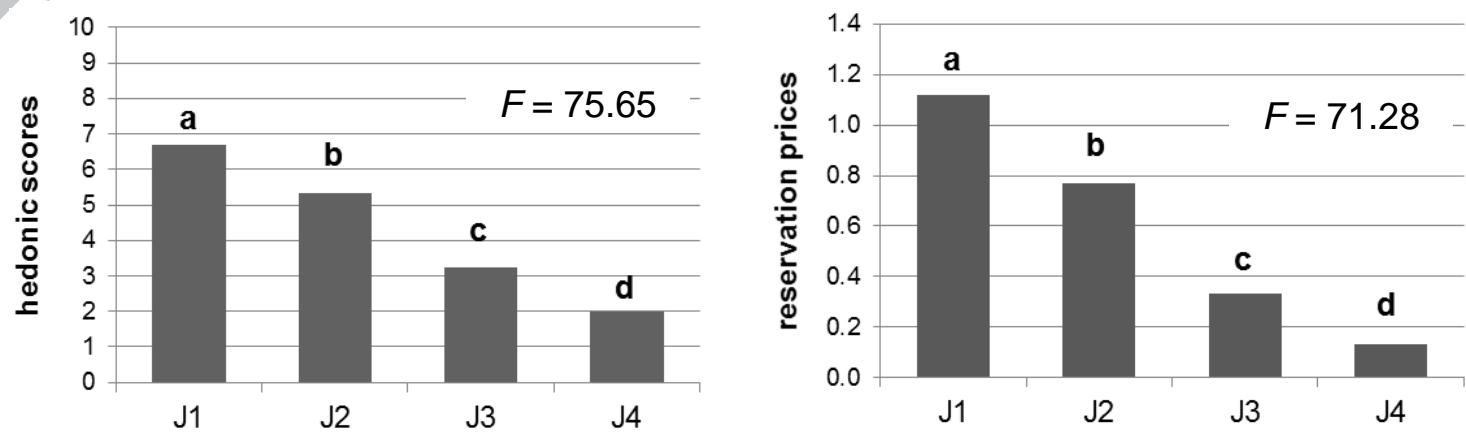